\title{
Evaluating mobile centric information access and interaction compatibility for learning websites
}

\author{
Baldreck Chipangura \\ University of South Africa \\ Pretoria, South Africa \\ chipab@unisa.ac.za
}

\author{
Judy van Biljon \\ University of South Africa \\ Pretoria, South Africa \\ vbiljja@unisa.ac.za
}

\author{
Adele Botha \\ CSIR \\ Pretoria, South Africa \\ abotha@csir.co.za
}

\begin{abstract}
Against the background of the global drive towards equal access to learning opportunities Open Distance Learning (ODL) institutions are challenged to optimize the use of technologies that provide usable, scalable and sustainable access. The remarkable mobile cellular growth together with the potential of mobile phones to be used as tools of communication, teaching and learning poses new challenges to educational institutions and specifically open-distance learning institutions. The aim of this article is to investigate the compatibility of mobile cellular phone web services that facilitate ubiquitous and sustainable information access and interaction in an open and distance learning environment in South Africa. The contribution of the paper is a proposed Mobile phone information access compatibility checklist extracted from literature and validated by its application on an ODL learning website.
\end{abstract}

Index Terms - information access, mobile centric access, mobile phone, mobi site

\section{INTRODUCTION}

Digital difference rather than a digital divide underlies the mobile centric approach that Africa and other developing countries are following to participate in the information society [1]. Although developed countries use mobile technology, developing countries are seen as more mobile centric. This is because alternative means are not available due to various infrastructural and physical realities [2]. One of the challenges of utilizing the digital difference paradigm is to provide meaningful content, services and interaction in a cost-effective manner using the technology that users already own [3]. This challenge is central to the provision of services in Open and Distance Learning (ODL) environments in developing countries such as South Africa and provides the rationale for this paper.

The primary focus of this article is to investigate the compatibility of mobile cellular phone web services that facilitate ubiquitous and sustainable information access and interaction in an open and distance learning environment in South Africa. This article therefore aims to articulate knowledge that is grounded in the realities of mobile service provision of Higher Education Institutions (HEIs).

The research is guided by the question: "How is the institution providing compatible mobile cellular technology web access to services that facilitate ubiquitous and sustainable information access and interactions in distance learning?"

The study is underpinned by the research done at the CSIR Meraka Institute on channel agnostic service provision through a mobile platform [4, 5]. The generic criteria outlined for Mobile Cellular Access provision within Higher Education
Institutions are used for benchmarking mobile information access in an ODL environment. Thus the criteria are outlined from the provision perspective, where this study interprets these for user access.

\section{RESEARCH CONTEXT}

The University of South Africa(Unisa)'s ODL policy is entrenched in providing open learning, student support, flexibility in methods and criteria for assessing the learning processes [6]. The diverse backgrounds of students enrolled at Unisa introduce disparities in levels of exposure to accessible technological infrastructure [7]. Towards catering for the diverse student population the university introduced a number of technological support initiatives to facilitate students' access and interaction with services and content. The technological support provided by the university includes video conferencing, e-learning portal, email, DVDs, telephone, and Short Messages Services (SMS) [8].

The technological support initiatives reduced learner support problems but could not address all problems because most rural and township students only access the resources at the university's regional administrative centers, and have no access at home [9]. Most of the disadvantaged students cannot afford to purchase computers and Internet resources. Furthermore, rural areas lack infrastructure that is required for the functioning of a computer such as electricity and broadband connection [10].

Mobile phones can overcome some of the technological constraints people in rural areas experience and enable them to participate in the information society. Given the prolific mobile phone adoption in South Africa, most students at the university have access to a mobile phone irrespective of their geographical residence, with over $90 \%$ mobile phone ownership [11]. The phenomenal growth in the mobile sector with the vast majority of the population gaining access to the information services and content has opened new challenges and opportunities for the university and raises questions on how the university should respond to students' needs. One such challenge is to prepare the university website to accommodate access by mobile phone users.

\section{MOBILE CELLULAR PHONE CHARACTERISTICS}

A mobile cellular phone is one type of mobile hand held device used by people for information access and interaction. Mobile cellular phones come in many different form factors. The handset form factor determines the scope of interaction with the phone and the type of content that a user can access. 
The keyboard and display screen sizes determine the user experience of the device [12]. Feature phone handsets have small display screens, ambiguous keyboards and no pointing devices, which negatively impact the user experience [13]. The small screen size affects readability, legibility and comprehension of the content when reading on the device's screen [13]. Mobile handsets that occupy the middle range and top range models have colored display screens, QWERTY keyboard and web browsers.

\section{MOBILE WEB APPLICATIONS}

A web page is an information system of interlinked hypertext documents accessed via the internet [14]. The social value of the web is to enable human communication, share knowledge and make commercial transactions. The mandate of the $\mathrm{W} 3 \mathrm{C}$ is to make these benefits available to people irrespective of their hardware, network infrastructure, culture and mental capabilities [15]. The W3C [15] prescribes to One Web concepts, which is explained as follows:

"One Web means making, as far as is reasonable, the same information and services available to users irrespective of the device that they are using. However, it does not mean that exactly the same information is available in exactly the same representation across all devices. The context of mobile use, device capability variations, bandwidth issues and mobile network capabilities all affect the representation...."

Despite the fact that $\mathrm{W} 3 \mathrm{C}$ provides standard guidelines for One web design, not all websites meet these standards. Research has shown that accessing websites that were designed for desktop computer access on mobile hand held devices results in negative user experience [12]. The reasons for the negative user experience are given as the small display screen, and constrained keyboard of handheld devices [13].

MobileOk checker is a tool that has been used for evaluating the mobile user experience of a number of university library websites [14, 16-18]. Lee[16] tested a total of 400 university websites all over the world and found that majority of the websites were not mobile phone compatible scoring between 0.16 and 0.21 on mobileOk Checker. Grigg, Bridges and Rempel [17] discussed strategies on how to create a mobile friendly website using the Oregon State University as an example. The study recommended that evaluating the mobile website using mobileOK checker would help in identifying bottlenecks that can be improved on. Mitchell and Suchy [19] used the mobileOk checker tool to evaluate four university websites for mobile phone compatibility and found that mobile access to university websites is still a long way to go. The mobileOK checker has also been used in other studies to identify mobile phone accessibility problems of university websites [14, 18].

At organizational level, many universities are struggling with adapting their current desktop-based websites to be accessible on mobile devices [20]. A number of researchers have looked into the problem and have proposed a number of mobile content adaption techniques. Some of the techniques are: webpage filtering technique [21], smart framework for web content and resources adaption [22], server side architecture for re-authoring existing websites [23].

Considering the provision of mobile information access services as described by the M4D model, a mobile platform solution should at a minimum meet the following functional and non-functional requirements [5]:

- Minimal Total Life Cycle Cost- built using low cost open source components that require minimal upfront expenditure with limited ongoing operating expenses in the form of licensing and support fees;

- Standards Compliant Solution- to ensure interoperability the selected solution should be based on open standards e.g. SOA, JAIN SLEE etc;

- Bearer \& Device Agnostic- allow for the same service to be accessed from different mobile devices using different access mechanisms;

- Flexibility And Extendibility - with reference to the addition of further communication mechanisms e.g. Near Field Communication, MMS, SIP etc;

- $\quad$ Ease of use and accessibility - making it easier to create, operate and maintain specific mobile services and reducing the required minimum skills levels;

- Synergies and Interoperability - with other HEI and relevant ICT solutions;

- Reusable Modules- ability to develop mobile services using new as well as existing reusable modules;

- Flexibility and Extendibility - Incorporating existing standalone mobile applications;

- Scalability - ensuring that the Mobile Delivery Platform can be scaled up to meet the anticipated concurrent user load;

- Availability - ensuring that the platform is architected as a high availability solution;

- Ease of Use- ensuring that all users of the systems including end users, contributors and facilitators can interface with the solution using properly designed User Interface; and

- $\quad$ Leverage Available Skills - development and support of the selected solution should not require scarce specialised skills; with the basic set of Java and related development and support skills, available technical resources should be able to work on the solution.

In summary, the literature review has shown that mobile web information access is affected by factors that include the characteristics of mobile phone device, the user, the context of use, the mobile web application design and the information that the users want to access.

\section{RESEARCH METHODOLOGY}

This section discusses the research paradigm, design and sampling procedure used in this study.

\section{A. Research paradigm}

This research is grounded in the qualitative research paradigm. Qualitative research methods provide scope for formative evaluation of computer systems aimed at improving system design and use [24]. In the qualitative research approach the enquirer is a passionate participant who is immersed in the study context and is responsible for facilitating the construction of knowledge [25]. Qualitative research requires that the researcher coordinates data collection, deals with multi realities that exist in the context 
without influencing the research environment and the outcomes [26]. Qualitative research is selected, as all these apply to this study.

\section{B. Research design}

The research design of this study is based on the provision of mobile services as described by the M4D model, a Mobile platform solution [5]. This study selects mobile platform parameters as discussed in section IV, which are relevant to end user mobile web access at HEIs. The parameters selected were accessibility, mobi site compatibility, interoperability, and mobi site services as shown in Table 1.

TABLE 1. MOBI SITE EVALUATION CRITERIA

\begin{tabular}{|c|l|}
\hline Parameter & Features \\
\hline \multirow{4}{*}{ Accessibility } & Mobi site exists \\
\cline { 2 - 2 } & Main website has link to mobi site \\
\cline { 2 - 2 } $\begin{array}{c}\text { Mobi site } \\
\text { compatibility }\end{array}$ & $\begin{array}{l}\text { Mobi site ease of use rating on MobileOk } \\
\text { checker }\end{array}$ \\
\cline { 2 - 2 } & $\begin{array}{l}\text { Main website adaptability rating on MobileOk } \\
\text { checker }\end{array}$ \\
\hline \multirow{2}{*}{ Interoperability } & Twitter \\
\cline { 2 - 2 } & Facebook \\
\cline { 2 - 2 } & others \\
\hline \multirow{2}{*}{$\begin{array}{c}\text { Mobi site } \\
\text { services }\end{array}$} & Informational \\
\cline { 2 - 2 } & Interactive \\
\cline { 2 - 2 } & Resources \\
\hline
\end{tabular}

The University of South Africa was selected as the context of the study based on the fact that it is the only fully dedicated Open and Distance Learning University in the country. The procedure for data capturing in this research consisted of the following tests:

- Accessibility: the main university websites were tested for accessibility through a mobile cellular phone (Blackberry 9900). The following steps were followed:

- If accessible, does it reroute automatically to the mobile version of the website.

- If the main website does not reroute to the mobile version, does it have a visible link that a user can use to access the mobile version of the website.

- Alternatively, the mobi website was searched via Google to find if it exists using terms such as university name mobi site or university name mobile website.

- Mobi site compatibility: the mobi website was tested for mobile phone viewing compatibility using the $\mathrm{W} 3 \mathrm{C}$ MobileOK checker.

- Interoperability: the websites were checked to see if they provide services through mobile compatible platforms such as Twitter and Facebook.

- Mobi site services: the websites were evaluated on whether they offered mobile centric services.

\section{RESULTS AND DISCUSSION}

This section reports on the analysis of data obtained from investigating the compatibility of mobile cellular phone web services that facilitate ubiquitous and sustainable information access and interaction in an open and distance learning environment in South Africa.

\section{A. Mobile web accessibility}

The University of South Africa has three websites, the main university website, the e-learning portal, and the staff portal. The websites are separate entities but they have links to one another. Two of the websites, the main university website and the e-learning portal have both desktop version and the mobile version. Both versions of the websites were tested for accessibility through a mobile cellular phone. It was found that the desktop versions of the websites were accessible through the mobile cellular phone but were not adapted for such a platform. The websites did not automatically reroute to the mobile versions of the websites. Viewing the desktop versions of the websites through the mobile phone resulted in a negative user experience in the sense that the webpages took long time to download, the pictures on the sites were small and difficult to see, and the pages were too large for the mobile phone monitor requiring the user to scroll horizontally to view the contents of the page.

Having noticed that the desktop versions of the websites could not automatically reroute to the mobi site version of the page, we checked to see if there was a link on the site that routes to the mobile version. It was found that only the main website had a link to the mobile site version but the e-learning portal and the staff portal had no links to the mobi sites versions.

It was concluded that even though the university has made remarkable strides in providing mobile information access to its information systems resources minor connection problems still exists. Having developed the mobile access versions for the university websites but failing to provide functionality for automatic routing to the mobi sites detract from the user experience.

\section{B. Mobi site compatibility}

Three Unisa websites were tested for W3C Mobile Web Best Practices compatibility using W3C MobileOk Checker. Both the desktop versions and mobile versions of the websites were tested because when accessing the desktop websites through a mobile cellular phone it does not automatically redirect to the mobile version of the websites. The reason for testing both versions for compatibility is that a person can access the desktop version on a mobile device without knowing the URL for the mobile version. The reason for testing both versions was to find if the websites were compatible with the $\mathrm{W} 3 \mathrm{C}$ Mobile Web Best Practices standard.

Table 2, presents the W3C Mobile Web Best Practices compatibility results for the three websites that were tested (November 2012): the university's main website, the e-learning portal, and the staff portal.

TABLE 2. UNISA WEBSITES MOBILEOK CHECKER COMPATIBILITY RESULTS

\begin{tabular}{|l|l|c|}
\hline Website Purpose & Website Type & $\begin{array}{c}\text { W3C mobile } \\
\text { accessibility score }\end{array}$ \\
\hline \multirow{2}{*}{ E-learning Portal } & Mobi site version & $92 \%$ \\
\cline { 2 - 3 } & Desktop version & $90 \%$ \\
\hline \multirow{2}{*}{ Unisa main website } & Mobi site version & $91 \%$ \\
\cline { 2 - 3 } & Desktop version & $86 \%$ \\
\hline \multirow{2}{*}{ Staff Portal } & Desktop version & $14 \%$ \\
\hline
\end{tabular}


When accessing the university's main mobi site it was found to have links to pages that are not designed for mobile access, for example, clicking on the link My Studies from the mobi site home page links to the desktop version of the site. Many other links to pages that were not designed for mobile viewing were also found on the university's main mobi site.

\section{Mobile web interoperability}

The websites were checked to see if they provided access and interaction through popular mobile phone compatible platforms such as Twitter and Facebook. It was found that all the university websites provides services through mobile platform such as Twitter, Facebook and many other related social media platforms.

\section{Mobi site services}

The university provides mobile cellular technology tools for accessing university services, learning material, communication, and sharing knowledge. For the purposes of communication, the mobi sites are used for publishing university news, giving notices of upcoming events, provide university contact details, and advertise bursary information just to mention a few of the services. Such information is important especially to prospective high school students who mostly access websites through mobile cellular phones.

University mobi sites provide students with access to discussion forums. The discussion forums are accessible through the e-learning portal as well as through the social media platforms. Access to discussion forums benefits students in the sense that they can follow on a topic under discussion. The social media discussion forums focus on social aspects of student's life while the e-learning discussion forums focus on academic discourse among students.

Some of the mobi services that have been implemented and are operational at Unisa include SMS application tool, Interactive Voice Response (IVR) tool, Mobile Multiple Choice (MCQ) Assignment submission tool, student registration, and checking assignment submission status. In this section, we give an overview of these tools being used at Unisa.

\section{1) SMS application tool}

The tool is used to communicate important notifications such as exam results, due dates for assignment, exam dates, and registration dates to the students. SMS messages can be broadcasted to all the students, or directed to a group of students, for example, students registered for a specific course. SMS are also used to track courier parcels. A message indicating a track, trace number and dispatch date is forwarded to students.

Students use the SMS messaging tool to query the examination database for results, which is returned for viewing on their mobile phones.

2) Interactive Voice Response (IVR) tool

It is a tool that allows a computer to interact with humans using voice and Dual Tone Multi Frequency Signaling (DMTF) keypad inputs. IVR tool allows students to interact with the examination results database via mobile phone voice call. The tools uses a synthesized human voice that reads a simplified version of the portal content and the user can browse by dialing on the phone keyboard. Students access the IVR by dialing a given Unisa telephone number to get their results.

\section{3) Mobile Multiple Choice (MCQ) Assignment} submission tool

In an effort to improve assignment submission and meeting submission deadlines, Unisa developed a Java mobile information device profile MCQ assignment submission tool. The tool is downloadable from Unisa websites. To submit an assignment on the application, students must first login. The students are presented with a screen where they can capture answers to the assignment questions, submit answers, receive an immediate confirmation for a successful submission, and view the memorandum after submission.

Table 3 summarizes mobile cellular technology information access checklist as applied to the university websites.

TABLE 3. MOBILE PHONE INFORMATION ACCESS CHECKLIST

\begin{tabular}{|l|l|l|}
\hline Parameter & Features & $\begin{array}{l}\text { Availability } \\
\text { (Yes/No) }\end{array}$ \\
\hline Accessibility & Mobi site exisits & Yes \\
\cline { 2 - 3 } & Main website has link to mobi site & Yes \\
\cline { 2 - 3 } & Main website reroute to mobi site & No \\
\hline \multirow{4}{*}{$\begin{array}{l}\text { Mobi site } \\
\text { compatibility }\end{array}$} & See ratings in table 2 above & Yes \\
\hline \multirow{4}{*}{ Interoperability } & Twitter & \\
\cline { 2 - 3 } & Facebook & Yes \\
\cline { 2 - 3 } services & others & Yes \\
\hline \multirow{4}{*}{\begin{tabular}{l} 
Mobi site \\
\cline { 2 - 3 }
\end{tabular}} & SMS & Yes \\
\cline { 2 - 3 } & Voice Response & Yes \\
\cline { 2 - 3 } & MCQ assignment submission & Yes \\
\cline { 2 - 3 } & Student registration & Yes \\
\cline { 2 - 3 } & Check assignment status & Yes \\
\hline
\end{tabular}

\section{CONCLUSION}

This study investigated the compatibility of mobile cellular phone web services that facilitate ubiquitous and sustainable information access and interaction in an open and distance learning environment in South Africa. The findings from this study have shown that the university websites are mobile phone compatible as depicted by high scores recorded on the mobileOk Checker tool. This contradicts studies [16, 19], who found most university websites to be mobile phone incompatible. Even though the university websites scored high on the mobileOK Checker tool, it was found that within a mobi site there are links that route to the desktop version of the website. This results in a negative user experience when such links are visited from a mobile phone. It was also found that when visiting the main websites through a mobile phone, the websites could not automatically reroute to the mobi site versions. This implies that if a person does not know the mobi site address, would have a bad user experience navigating the site. The findings of this study supports the findings of [16], who found that by using mobileOk Checker evaluation tool, the mobile phone compatibility of websites can be improved.

The contribution of the paper is a mobile phone information access compatibility checklist extracted from literature and validated by its application to an ODL learning website. Together with the W3C MobileOK Checker compatibility tool, this checklist can be used in evaluating the mobile phone information access and interaction provision of any learning website. The checklist needs further testing at other institutions to verify its completeness and reliability. 


\section{REFERENCES}

[1] A. Botha, "Mobile learning-an African perspective," in Satellite ICCR09 Workshop on Innovative Mobile Technology \& Services for Developing Countries, Durban South Africa, 2010, pp. 1-8.

[2] J. Donner and S. Gitau, "New paths: Exploring mobile-centric internet use in South Africa", Presented at Africa Perspective on the Role of Mobile Technologies in Fostering Social Development. 2009, Available: http://www.w3.org/2008/10/MW4D_WS/papers/donner.pdf. (accessed 04 June 2013)

[3] A. Botha, I. Makitla, F. Ford, T. Fogwill, D. Seetharam, C. Abouchabki, J. Tolmay and O. Oguneye, "Mobile phone in Africa: Providing services to the masses," in CSIR 3rd Biennial Conference 2010, Science Real and, Relevant, CSIR International Convention Center, Pretoria, South Africa, 2010, pp. 6-12.

[4] A. Botha, I. Makitla, J. Tolmay, M. Ford, D. Seetharam, L. Butgereit, O. Ogunleye and C. Abouchabki, "Mobile4D platform," in IST-Africa, 2010, 2010, pp. 1-7.

[5] I. Makitla, M. Herselman, A. Botha and D. Van Greunen, "Accesstechnology agnostic conceptual model," in Proceedings of M4D2012, New Delhi, India, 2012, pp. 211-222.

[6] ODL Policy. Available: http://www.unisa.ac.za/cmsys/staff/contents/departments/tuition_policie s/docs/OpenDistanceLearning_Council3Oct08.pdf. 2008. (accessed 04 June 2013)

[7] I. P. Sonnekus, W. Louw and H. Wilson, "Emergent learner support at University of South Africa: An informal report," Progressio: South African Journal for Open and Distance Learning Practice, vol. 28, pp. 44-53, 2006.

[8] A. van Rooyen, "Integrating mobile technology into a distance education accounting module," in Proceedings of the 3rd International Conference on e-Learning, 2008, pp. 475.

[9] K. P. Quan-Baffour, "Managing a tutorial system: The Unisa ABET experience," Progressio: South African Journal for Open and Distance Learning Practice, vol. 27, pp. 36-43, 2005.

[10] C. Fuchs and E. Horak, "Africa and the digital divide," Telematics Inf., vol. 25, pp. 99-116, 2008.

[11] M. Makoe, "Exploring the potential for MXit- a cellphone instant messaging system in supporting distance learners," The Journal of Open, Distance and e-Learning, vol. 25, pp. 251-257, October, 2010.

[12] Y. Cui and V. Roto, "How people use the web on mobile devices", Presented at Proceeding of the 17th International Conference on World Wide Web. 2008, Available: http://dl.acm.org/citation.cfm?id=1367619 (accessed 04 June 2013).

[13] Y. Yesilada, S. Harper, T. Chen and S. Trewin, "Small-device users situationally impaired by input," Comput. Hum. Behav., vol. 26, pp. 427-435, 2010.

[14] I. Marin and A. Rionda. (04 Feb 2008). W3c mobileok basic tests 1.0 checker (beta release) user manual [W3C MobileOk Checker].
Available: http://dev.w3.org/2007/mobileok-ref/mobileOK-Basic-RI1.0-UserManual.pdf (accessed 04 June 2013).

[15] J. Rabin and C. McCathieNevile. (02 Nov 2006). Mobile web best practices 1.0. Available: http://www.w3.org/TR/2006/PR-mobile-bp20061102/ (accessed 04 June 2013).

[16] D. Lee, "Toward mobile-friendly libraries: The status quo," in Theory and Practice of Digital Libraries, Lecture Notes in Computer Science, Paphos, Cyprus, 2012, pp. 38-50.

[17] K. Griggs, L. M. Bridges and H. G. Rempel, "Library/mobile: Tips on designing and developing mobile web sites", Code4lib Journal [http://journal.code4lib.org/articles/2055]. (8), 2009 (accessed 04 June 2013).

[18] S. Houghton, "Mobile services for broke libraries: 10 steps to mobile success," The Reference Librarian, vol. 53, pp. 313-321, 2012.

[19] C. Mitchell and D. Suchy, "Developing mobile access to digital collections," D-Lib Magazine, vol. 18, pp. 2, 2012.

[20] A. W. Aldrich. (24 June 2010). Universities and Libraries Move to the Mobile Web. Available: http://www.educause.edu/EDUCAUSE+Quarterly/EDUCAUSEQuarterl yMagazineVolum/UniversitiesandLibrariesMoveto/206531.(accessed 04 June 2013).

[21] T. Bickmore, A. Girgensohn and J. W. Sullivan, "Web page filtering and re-authoring for mobile users", The Computer Journal, vol. 42, pp. 534, 1999.

[22] S. K. Guirguis and M. A. Hassan, "A smart framework for web content and resources adaptation in mobile devices," in Advanced Communication Technology (ICACT), 2010 the 12th International Conference on, Phoenix Park, 2010, pp. 487-492.

[23] J. Nichols, Z. Hua and J. Barton, "Highlight: A system for creating and deploying mobile web applications," in Proceedings of the 21st Annual ACM Symposium on User Interface Software and Technology, Monterey, California, USA, 2008, pp. 249-258.

[24] B. Kaplan and D. Duchon, "Combining qualitative and quantitative methods in information systems research: a case study," Mis Quarterly, pp. 571-586, 1988

[25] Y. S. Lincoln and E. G. Guba, "Naturalistic Inquiry", Sage Publications, Inc, 1985.

[26] T. A. Schwandt, "Three epistemological stances for qualitative inquiry," in Handbook of Qualitative research, 2nd ed. CA, USA: Sage Thousand Oaks, CA, 2000, pp. 189-213. 